\title{
TRILHA INTERPRETATIVA: ALIANDO ATIVIDADE FÍSICA AOS CONCEITOS BIOLÓGICOS NUMA PROPOSTA DE EDUCAÇÃO AMBIENTAL
}

\author{
Cisnara Pires Amaral ${ }^{1}$ \\ Mário Luiz Corcini Carvalho² \\ Cadidja Coutinho ${ }^{3}$
}

Resumo: A atividade realizada entre as disciplinas de Educação Física e Biologia teve o intuito de proporcionar aprendizado, conhecimento científico e atividade física em trilha com arvorismo realizada no interior do município de Santiago/RS. Para tal, os discentes foram conduzidos ao distrito de Ernesto Alves onde fotografaram a organologia vegetal e suas peculiaridades, realizando um glossário do Reino Plantae. O trabalho proporcionou contato com a natureza, identificação de espécies visualizadas no livro didático, evidenciou o prazer dos discentes em realizar atividade em um espaço não-formal, constatando que trilhas não servem apenas para entretenimento e, sim, como ferramenta para aprendizado e conhecimento.

Palavras-chave: Espaço Não-formal; Conhecimento Científico; Arvorismo; Educação.

Abstract: The activity held between the disciplines of Physical Education and Biology had the purpose of providing learning, scientific knowledge and physical activity in trail with tree climbing held in the countryside of the municipality of Santiago. To do this, the students went to Ernesto Alves district where they photographed the organology plant and its peculiarities, making a glossary of the Kingdom Plantae. The work resulted in contact with the nature, identification of species displayed in the textbook, showed the pleasure of the students during this activity in a non-formal space, noting that trails are not just entertainment but rather as a tool for learning and knowledge.

Keywords: Non-formal Space; Scientific Knowledge; Guidance; Education.

\footnotetext{
1 Universidade Regional Integrada do Alto Uruguai e das Missões, URI/Santiago. Mestre em Tecnologia Ambiental. Email: cisnara@yahoo.com.br

2 Escola Estadual Cristóvão Pereira. Professor de Educação Física, Especialista em Supervisão Escolar. E-mail: mlcorcini@yahoo.com.br.

3 Universidade do Pampa, câmpus Dom Pedrito/RS. Dra em Educação em Ciências. E-mail: cadidijabio@gmail.com.
} 


\section{Introdução}

Vivenciamos uma época em que os adolescentes estão cada vez mais introspectivos, preocupados, principalmente, com suas redes sociais, atrelados a diferentes tipos de aparelhos eletrônicos. Convivemos não só com o descaso em relação à educação, falta de motivação e interesse em sala de aula, como também com a negligência em relação às questões ambientais e à valorização dos espaços naturais.

Os adolescentes vivenciam o consumismo, a falta de consciência em relação ao reaproveitamento de produtos, a dificuldade em valorizar a natureza e suas interações. Vivenciamos a era do vídeo game, na qual as interações se estabelecem no interior de suas casas ou apartamentos.

Isaías Faro (2017, p.75) observa:

O estímulo ao desejo de consumo pelo consumo, de ter por ter, para possuir, ter para ostentar, respondendo a instâncias internas mais profundas do indivíduo, parece estar na raiz do consumo exagerado. A isso, dá-se o nome de "consumismo". A questão da sustentabilidade ou da capacidade de gestão do descarte destinado a aterros sanitários não é, todavia, uma preocupação para o cidadão comum, mas deveria ser e, na perspectiva do desenvolvimento de uma consciência ambiental voltada para a preservação da natureza e, pois, das condições ideais à vida do planeta.

Dessa forma, por que não utilizar espaços não-formais para produzir um aprendizado ambiental? Como proporcionar a autocrítica em relação ao descaso com os recursos naturais? Como auxiliar o discente a entender a importância do equilíbrio entre os ecossistemas? Como realizar atividades interdisciplinares que promovam bem-estar e conhecimento científico?

Entendemos a importância de diferentes metodologias para oportunizar aos discentes novas formas de aprendizado, realizando a aproximação entre conhecimento científico e o conhecimento cotidiano, estimulando a integração homem-natureza e auxiliando a autocrítica em relação ao reaproveitamento de materiais e suas consequências para o meio.

Assim, as trilhas interpretativas podem favorecer o contato com as relações que se estabelecem no meio, instigam o conhecimento e auxiliam na aprendizagem. Elas se constituem em espaços para promoção da Educação Ambiental (EA) formal e não-formal, superando a concepção de ações de visitação para a sensibilização no modo como as pessoas pensam e avaliam a sua relação com o ambiente (CAMPOS: FILLETO, 2011; EISENLOHR et al., 2013).

Sendo assim, Souza (2014, p. 247) afirma que: 
A trilha é metodologia fundamental no processo de sensibilização ambiental, prioritariamente da EA não formal. Essa afirmação se justifica por se acreditar que esse ambiente seja mais propício à sensibilização devido à possibilidade de contato da pessoa com a natureza e, assim, a mesma é condicionada a perceber, observar e analisar o ambiente pelo qual está de passagem, podendo despertar nela a vontade de preservar e conservar.

A utilização das trilhas permite, também, a construção de conhecimentos científicos significativos, estimula ganhos cognitivos e relacionados às dimensões sociais e afetivas, melhoria na autoestima, no senso de responsabilidade individual e coletiva e na manutenção da cidadania (COSTA et al., 2014).

Ainda que a maioria das atividades em trilhas que tentam aproximar a vivência e aprendizado de campo ao currículo escolar sejam citadas como trilhas ecológicas, acreditamos ser importante nominar como Trilhas Educativas, uma vez que buscam os referenciais de aprendizagem, diferenciando-as daquelas que são características de um público que busca turismo e lazer, mesmo considerando que ambas são importantes no processo de disseminação da EA (ROCHA et al., 2016).

Assim, a EA, em conjunto ao ambiente da trilha, aparece e se firma como metodologia ímpar em processos de sensibilização ambiental, já que permite uma assimilação entre conhecimentos adquiridos e percepções no próprio ambiente natural, propiciando situações e condições mais positivas para reflexões e percepções (SOUZA, 2014).

Desse modo, o intuito do trabalho foi de oportunizar aos discentes atividades que proporcionem, além do entretenimento, as interfaces entre a atividade física e o conhecimento biológico, a releitura de espaços onde ocorre a integração entre fatores bióticos e abióticos, estimulando a sensibilização humana, a troca entre os pares, a ressignificação de conceitos e a percepção em que são necessárias retomada de atitudes para a manutenção e equilíbrio do meio.

\section{Educação Ambiental e interdisciplinaridade}

A revolução industrial abriu novos caminhos para converter energia e produzir bens. Com isso, libertou a humanidade de sua dependência do ecossistema à sua volta. Os humanos derrubaram florestas, drenaram pântanos, represaram rios, inundaram planícies, construíram ferrovias e edificaram metrópoles. Enquanto o mundo era moldado para atender às necessidades do Homo sapiens, habitats e espécies foram extintas. Nosso planeta, um dia verde e azul, está se tornando um shopping center de plástico e concreto (HARARI, 2018). 
Desastres ambientais vêm se tornando constantes, atingem a população em uma proporção cada vez mais assustadora, sendo uma reação que a natureza dá em resposta ao descaso. Riqueza e luxo são o que muitos querem e nada disso pode ser conquistado sem que haja poder sobre os recursos naturais. Mas a natureza reage à ausência de equilíbrio e não escolhe suas vítimas, todos se tornam alvo fácil (SANTOS; ALMEIDA, 2011).

Assinala Isaías Faro (2017, p.17):

Trata-se, na verdade, de problema de dimensões planetárias, com implicações civilizacionais, mas que, de fato, afeta toda a espécie viva. Por outro lado, as nações se mobilizam deixando, porém, a desejar para um assunto tão complexo e importante. Uma pequena parte da sociedade, no entanto, faz algo de forma ainda acanhada e pouco se aprofunda no conhecimento sobre o assunto. Outros não acreditam no que pode acontecer, mas a mobilização é crescente e, por isso, não podemos deixar que essa atitude enfraqueça.

Seguindo a perspectiva do autor acima, como nós, educadores, poderemos atrelar as nossas práticas de ensino ao impacto ambiental que nosso século enfrenta? Como poderemos desenvolver em nossos alunos a consciência ambiental reflexiva? Como auxiliar para que compreendam que nossas ações estão relacionadas? Que interferem na vida do outro e do meio ambiente?

Acreditamos que, para alcançar esses objetivos, devemos dar importância para as práticas educativas, para a correlação entre as disciplinas escolares e para a importância das ferramentas didáticas utilizadas pelo docente. Nessa perspectiva, a interdisciplinaridade torna-se peça fundamental, capaz de unir disciplinas e proporcionar discussões sobre o conhecimento científico e o mundo cotidiano, capaz de relacionar à EA e suas interfaces com o cotidiano escolar.

Destarte, a EA não deve ser limitada a um conteúdo ou disciplina específica. Deve, sim, transitar entre as diversas áreas do conhecimento, sendo abordada em diferentes contextos e públicos-alvo, possibilitando a mediação e construção do conhecimento em conjunto entre alunos e professores (BRANCALIONE, 2016).

A questão ambiental possibilita o diálogo entre os diferentes saberes, buscando a articulação teórica das ciências em métodos interdisciplinares em prol do meio ambiente (LEFF, 2012). Além disso, as temáticas da natureza devem se integrar ao currículo através da transversalidade, discutidas nas diferentes áreas do conhecimento, visando uma interpretação abrangente da questão ambiental.

Assim, enfatizam os Parâmetros Curriculares Nacionais (PCN): 
A proposta de trabalhar questões de relevância social, na perspectiva transversal, aponta para o compromisso a ser partilhado por professores de todas as áreas, uma vez que é preciso enfrentar os constantes desafios de uma sociedade que se transforma e exige continuamente dos cidadãos à tomada de decisões em meio a uma complexidade social crescente (BRASIL, 1998, p.50).

Lisboa e Kindel (2012) observam que a transversalidade é uma aposta valorosa por sua potencial forma de corresponsabilizar a todos e a cada um pelo entendimento e pela consequente proteção do ambiente como patrimônio de qualquer ser vivo.

Sendo assim, é notória a importância de ações interdisciplinares e transversais que auxiliem a integrar o currículo com o espaço onde vivemos. A interdisciplinaridade requer, primeiramente, atitude diante dos desafios apresentados e o não engessamento do educador. Requer uma prática constante e, ao mesmo tempo, incessante, pois o professor deixará de ser apenas alguém que ensina conteúdo para ser um educador-pesquisador, e isso significa realizar uma autocrítica do seu próprio trabalho a todo o momento (MARTINS; TAVARES, 2015).

Quando o professor disponibiliza ao estudante estratégias de ensino diferenciadas, como atividades que permitam o contato direto com a natureza, esses passam a compreender os fenômenos naturais e a sua importância de maneira prática. E, assim, conseguem associar a teoria vista em sala de aula com o meio prático, valorizando o seu aprendizado (LAZZARI et al., 2017). Além disso, usar a EA para proporcionar o contato com a natureza, o conhecimento da flora da região e suas características torna o ensino mais coerente, dinâmico e instigador.

Assim sendo, entendemos que a EA é vista como uma alternativa para sensibilização da sociedade frente à importância dos recursos naturais. Uma vez sensibilizado e com conhecimento sólido sobre a relevância da biodiversidade, os cidadãos atuam como agentes multiplicadores do conhecimento criando, assim, uma rede em prol da conscientização e proteção dos recursos naturais.

Corroboram Silva, Samarco e Teixeira (2012) ao reconhecer que em qualquer fase da vida é importante a abordagem da alta sociabilização, da cooperação, do lazer e da EA. Isso possibilita agir como facilitadores para o despertar de hábitos saudáveis tanto no indivíduo como no coletivo, gerando efeito multiplicador.

Ainda assinalam os PCN: 
O trabalho de Educação Ambiental deve ser desenvolvido a fim de ajudar os alunos a construírem uma consciência global das questões relativas ao meio para que possam assumir posições afinadas com os valores referentes à sua proteção e melhoria. Para isso, é importante que possam atribuir significado àquilo que aprendem sobre a questão ambiental. E esse significado é resultado da ligação que o aluno estabelece entre o que aprende e sua realidade cotidiana(...) (BRASIL, 1997, p.30).

Mais uma vez, deparamo-nos com a possibilidade de tornar o ensino mais interessante e instigador, utilizando o meio ambiente como eixo para sensibilização e reflexão. Entendendo a importância da preservação do ambiente para o estudo, atrelando o conhecimento científico a ludicidade, torna-se possível conhecer as características de espécies que poderiam ser somente visualizadas em um livro didático.

Silva 2007, p. 130, relata:

Não estamos aqui apenas propondo a valorização dos ambientes naturais para um melhor viver humano, mas, sim, identificando o quanto é possível perceber-se, apreciar e dedicar-se para a preservação das florestas, das águas, dos seres humanos e não humanos, dos nossos ambientes naturais e culturais, pelo seu valor em si mesmos, pelas possibilidades lúdicas que oferecem, pela biodiversidade existente e pelo simples fato de existirem no mundo.

Assim, a sensibilização e a expressão de um grupo podem ser medidas pela reação a atividades do encontro, como numa trilha interpretativa, que desafia e provoca a sensibilidade aos estímulos da natureza representados por formas, texturas, cores, sons e cheiros (BOHRER; KROB, 2012).

De acordo com Brancalione (2016), pensar o meio ambiente na sua complexidade, exigir habilidades e competências, ou investigar criticamente, são fatores que fazem uma relação direta entre sujeito e sua inserção no meio. A concretização desses projetos fortalecerá o sentimento de ação do indivíduo.

A falta de atividades práticas, exemplos concretos ou de oportunidades para a visualização de diferentes processos pode reduzir o desenvolvimento de uma percepção holística acerca dos temas trabalhados em sala de aula. Oportunidades diferenciadas, como trilhas interpretativas, permitem aos estudantes desenvolver novas habilidades relacionadas à conexão dos conhecimentos e sua aplicação nas mais diferentes situações do cotidiano (LAZZARI et al., 2017). 
Diante disso, devemos buscar a sensibilidade ambiental, no reconhecimento de pertencer ao meio, sendo responsável pela sua manutenção, proporcionando criticidade e aprendizado em trilha educativa.

\section{Materiais e Métodos}

Considerando que as propostas de EA devem ser caracterizadas por iniciativas transversais e interdisciplinares, a presente atividade foi idealizada por docentes de Educação Física e Ciências Biológicas, realizada com uma turma de $3^{\text {a }}$ série do Ensino Médio de uma escola particular de Educação Básica do município de Santiago/RS, totalizando uma amostra de 35 discentes. Para tal, os mesmos foram conduzidos a um distrito municipal sob as seguintes coordenadas geográficas $29^{\circ} 21^{\prime} 49^{\prime \prime} \mathrm{S}$ e $54^{\circ} 43^{\prime} 33^{\prime \prime W}$. Esse distrito é conhecido pelas belezas naturais e áreas de matas preservadas, e permitem a realização de atividades junto à natureza, como, por exemplo, trilhas ecológicas.

Assim sendo, o trabalho contou com trilha interpretativa e arvorismo, perfazendo um tempo de 2 horas de atividade. Previamente à realização da trilha, o professor de Educação Física montou, em pontos estratégicos, cordas entrelaçadas em árvores, técnica conhecida como arvorismo ou arborismo, que consiste em percorrer um caminho da mata em uma plataforma suspensa na altura das copas das árvores.

A ideia consistia em que os discentes realizassem a trilha e, em dois pontos, utilizassem as cordas suspensas para continuar o passeio, tornando a trilha também uma opção de atividade física.

Antes do início do trajeto, os professores orientaram os alunos para que aproveitassem o máximo o contato com a natureza, que observassem as interações existentes no local e quais seriam as consequências, acaso uma grande quantidade de lixo fosse disposta no mesmo. No trajeto, deveriam explorar o meio da melhor forma, percebendo as espécies vegetais que compunham a região, relação de equilíbrio do meio, deveriam fotografar os vegetais e as interações ecológicas visualizadas, observando a morfologia das raízes, caules, folhas, flores, sementes e alguns aspectos da fisiologia, como exsudação, transpiração, mecanismos de defesa.

A atividade continuou em sala de aula, onde realizou-se um glossário do Reino Plantae, descrevendo a organologia vegetal, suas curiosidades em relação à morfologia e fisiologia e as principais interações estabelecidas entre as plantas. Para isso, os alunos apresentaram suas fotos impressas e, em grupos de 4 indivíduos, iniciaram a produção do glossário, identificação das partes do vegetal, suas curiosidades, interações e classificação em briófitas, pteridófitas, gimnospermas e angiospermas.

Após o término da atividade, realizou-se um questionário semiestruturado para a coleta de dados em relação à atividade proposta, que

constava das seguintes perguntas: a significância da atividade, o 
entretenimento em relação à trilha, a dificuldade em relação ao exercício físico realizado, a percepção das características das espécies e sua analogia com o livro didático, o conhecimento científico proporcionado e a interdisciplinaridade entre as disciplinas. Após a coleta, ocorreu a análise e tabulação dos dados.

\section{Resultados e Discussão}

Os dados aqui apresentados são resultantes dos 35 questionários respondidos pelos alunos participantes da atividade. A Tabela 1 relata a significância da atividade proposta, através do seguinte questionamento: "Valeu a pena sair em um sábado à tarde para realizar uma trilha interpretativa que priorizava os conceitos explícitos em sala de aula?"

Tabela 1: Faz referência ao sentido da atividade realizada.

\begin{tabular}{ccc}
\hline $\begin{array}{c}\text { Significância da } \\
\text { atividade }\end{array}$ & Quantidade & Percentual \\
\hline Sim & 35 & $100 \%$ \\
Em parte & 0 & $0 \%$ \\
Não & 0 & $0 \%$ \\
Total & 35 & $100 \%$ \\
\hline
\end{tabular}

Fonte: Elaborado pelos autores.

Através da análise dos resultados observamos que os discentes possivelmente gostaram da atividade realizada. A atividade estimulou 0 conhecimento científico em espaço diversificado, a união entre a turma, pois auxiliavam uns aos outros durante a trilha. Também foi possível colocar em prática o entretenimento relacionado ao conhecimento, analogias e questionamentos entre os grupos. Acreditamos que, além do conhecimento biológico relacionado ao estudo da botânica, oportunizamos a promoção da EA.

Outro fato a considerar foi a possibilidade de aliar o estudo à tecnologia, pois os discentes utilizaram seus aparelhos de telefones para realizar as fotos. Presenciamos comparações entre as fotos, auxílio na identificação de algumas espécies, curiosidades e questionamentos em relação a outras, ou seja, uma interpretação ambiental. Fato este que aproxima a atividade proposta ao contexto e aos interesses dos alunos, facilitando a aceitação e a satisfação em realizar as demandas estipuladas pelo docente.

Para Santos, Flores e Zanin (2011), a interpretação ambiental é uma oportunidade de desenvolvimento humano que estimula a capacidade investigadora, levando o homem a repensar seu modo de ver e sentir o planeta como um todo, a partir da leitura e da percepção da realidade ambiental. Dessa forma, a natureza se firma como ferramenta facilitadora do aprendizado; concebe-se a educação biológica como estratégia para a proteção dos recursos naturais. 
Consideramos que a trilha, como a exemplificada por este trabalho, é uma metodologia fundamental no processo de sensibilização ambiental, prioritariamente da EA não formal. Essa afirmação se justifica por se acreditar que este ambiente seja mais propício à sensibilização devido à possibilidade de contato da pessoa com a natureza e, assim, a mesma é condicionada a perceber, observar e analisar o ambiente onde está, podendo despertar a vontade de preservar e conservar (SOUZA, 2014).

Entretanto, nem todas as trilhas se mostram ideais para a prática da EA, sendo desejáveis alguns atributos para que os visitantes vivenciem diversos tipos de experiências que os sensibilizem no sentido de sua integração com a natureza (EISENLOHR et al., 2013, p. 409). É imprescindível conhecer o local previamente, evitando transtornos para o meio ambiente e desconfortos para os discentes, pois ainda compreendemos que o conhecimento de áreas preservadas, sem a ação humana, é capaz de encantar e sensibilizar as pessoas com sua beleza.

A Tabela 2 está relacionada ao seguinte questionamento: "Você acha que a trilha realizada proporcionou lazer tanto quanto um game em uma rede social?".

Tabela 2: Relaciona a trilha ao entretenimento.

\begin{tabular}{ccc}
\hline Trilha & Quantidade & Percentual \\
Entretenimento & & $68,57 \%$ \\
\hline Sim & 24 & $11,42 \%$ \\
Em parte & 4 & $20 \%$ \\
Não & 7 & $100 \%$ \\
Total & 35 & \\
\hline
\end{tabular}

Fonte: elaborado pelos autores.

Nota-se $68,57 \%$ dos discentes relacionaram o lazer e o entretenimento à trilha interpretativa, $20 \%$ não conseguiram estabelecer a relação de bem-estar propiciado pelas trilhas. Como os questionários eram semiestruturados, os alunos poderiam justificar suas respostas. Alguns relatos podem ser exemplificados pelos trechos: "ainda sou muito fã de meus jogos", "até gostei, pois passaria a tarde de sábado na frente do meu computador", "eu gosto de estar no meio da natureza, mas ainda tenho que aprender a retirar da natureza as coisas boas", "senti muita paz de espírito", "nada é melhor que meus jogos kkk", "por mais momentos assim", "sábado especial, amei", "tinha vindo só por que era um trabalho, mas iria perder um ótimo passeio".

As narrativas apresentadas pelos participantes se aproximam dos estudos que afirmam que os adolescentes têm menos interesse e preocupação sobre as questões ambientais do que estudantes mais jovens ou mais velhos (UITTO; SALORANT, 2010, LIEFÄNDER et al., 2013; OLSSON; GERICKE, 2016). 
Sabemos que a geração atual, muitas vezes, vive reclusa em suas casas e dificilmente é atraída para atividades de lazer ou prática de atividade física com a família e amigos. A era da tecnologia está formando pessoas sedentárias, obesas, com várias síndromes e experts em jogos; que não sabem se relacionar com a natureza, não conseguem observar as relações que se estabelecem nesse meio. Acreditamos que momentos como os descritos nesta pesquisa, uma trilha interpretativa, proporcionam a troca de saberes, a criticidade, o questionamento e o contato com o meio ambiente.

Cabe destacar a função do professor em promover atividades que estimulem os discentes a aplicar o conteúdo teórico descrito em sala de aula em vivências práticas e repletas de sensações (afetivas, emocionais, cognitivas, ...).

Bacich e Moran (2018) afirmam que o papel do professor, hoje, é muito mais amplo e complexo. Não está centrado só em transmitir informações de uma área específica; ele é principalmente designer de roteiros personalizados e grupais de aprendizagem e orientador/mentor de projetos profissionais e de vida dos alunos. $O$ aprender se torna uma aventura permanente, uma atitude constante, um progresso constante.

Portanto, no caminho do efetivar a EA, ao professor incumbe a tarefa essencial de apontar o trajeto aos educandos, criar situações em que estes ajam de forma construtiva, de modo a desenvolverem competências e habilidades, e possam refletir de forma crítica sobre a realidade de modo a adquirirem a consciência da necessidade da conservação ambiental.

Contudo, é importante entender que não se deve idealizar a educação escolar como a única capaz de resolver e/ou apontar o caminho da resolução de todos os problemas sociais e ambientais da atualidade - este é um processo mais amplo e muito mais complexo (AGUIAR et al., 2017).

Como descrito anteriormente, o presente trabalho visou, também, a aproximar diferentes áreas do conhecimento numa proposta de Educação Ambiental, principalmente no que se refere a atividade física e os conceitos biológicos. Assim sendo, a Tabela 3 relaciona a dificuldade física apresentada pelos alunos em relação ao trajeto estabelecido, conforme o questionamento "Você sentiu dificuldade física em realizar o trajeto descrito e o arvorismo apresentado?"

Tabela 3: Faz referência a atividade física e o trajeto da trilha.

\begin{tabular}{ccc}
\hline $\begin{array}{c}\text { Dificuldade na } \\
\text { atividade física }\end{array}$ & Quantidade & Percentual \\
\hline Sim & 13 & $37,14 \%$ \\
Em parte & 9 & $25,71 \%$ \\
Não & 12 & $34,28 \%$ \\
Total & 35 & $100 \%$ \\
\hline
\end{tabular}

Fonte: Elaborado pelos autores. 
Percebe-se que os quesitos "em parte" e o "sim" têm um número considerável, apresentando $62,85 \%$ dos resultados. Deparamo-nos com as questões relacionadas à falta de atividade física e o sedentarismo. A comodidade de estar na frente de uma televisão ou computador facilitam o acúmulo de gordura no organismo, propiciam doenças e evitam a troca de relações entre as pessoas. Entendemos que atividades interdisciplinares, como as aqui relatadas, tornam as disciplinas mais interessantes e instigadoras, pois poderia ter sido apenas uma caminhada em um trajeto existente na mata, porém planejamos uma atividade desafiadora no momento em que atrelamos o arvorismo ao trabalho, aliando teoria à prática e propiciando as relações interpessoais e científicas.

A natureza é interdisciplinar e todos os seus filhos - seres vivos coexistem de modo integrado e atuante. A Terra é um sistema complexo que se auto organizou a partir do caos. Desenvolver sensibilidades para a percepção de si, do outro e do ambiente e a descoberta de suas funcionalidades é ensiná-los a aprender sobre o maravilhoso assombro que é a Vida. Coligar o homem a sua natureza e a natureza externa e contribuir para a expressão dessas interações será o papel do educador do presente que mediará estudos e ações que deverão superar no futuro, os desafios que estão postos no mundo (FAZENDA; CASEDEl, 2012).

Cada disciplina escolar é marcada por uma base epistemológica que a justifica e Ihe dá a devida importância no contexto da educação básica. Os tempos atuais ampliaram esta seara de competência disciplinar, mas, ao mesmo tempo, revelaram a ineficiência de uma só disciplina explicar os diversos e complexos fenômenos da vida atual (FORTUNATO; CONFORTIN; SILVA, 2013).

Para que os alunos possam compreender a complexidade e amplitude das questões ambientais, é fundamental oferecer-lhes, além da maior diversidade possível de experiências, uma visão abrangente que englobe diversas realidades e, ao mesmo tempo, uma visão contextualizada da realidade ambiental (LISBOA; KINDEL, 2012).

A Tabela 4 observa a percepção das características das espécies e sua analogia com o livro didático, através do questionamento: "As espécies visualizadas a olho nu relacionavam as mesmas características das gravuras observadas no livro didático (LD)?"

Tabela 4: Faz referência a percepção das características das espécies e sua relação com o livro didático

\begin{tabular}{ccc}
\hline $\begin{array}{c}\text { Característica e } \\
\text { analogia com o LD }\end{array}$ & Quantidade & Percentual \\
\hline Sim & 13 & $37,14 \%$ \\
Em parte & 17 & $48,57 \%$ \\
Não & 5 & $14,28 \%$ \\
Total & 35 & $100 \%$ \\
\hline
\end{tabular}

Fonte: Elaborado pelos autores 
Observa-se que $37,14 \%$ dos discentes relacionaram que o livro didático traz as características de forma relevante, lembrando que, em muitos locais, essa ferramenta passa a ser uma das únicas capazes de dar um suporte para o estudo. Já $48,57 \%$ entendeu o significado da visualização a olho nu, a percepção de características pouco visualizadas, a riqueza dos detalhes e, o tipo de estrutura.

Reafirmamos a importância das práticas interdisciplinares para colocar o estudante a par de diferentes situações que promovam o aprendizado. Para Corti e Souza (2012), explorar as possibilidades individuais dos jovens e as possibilidades do mundo faz com que construam conhecimentos sobre si próprios, permitindo colocarem-se à prova, confirmando, negando e reformulando suas hipóteses. Corrobora Demo (2009) que é preciso redefinir o papel do professor: em vez de "instrutor", passar para orientador maiêutico, "coach".

Essa é a ideia, utilizar trabalhos interdisciplinares para que o professor, em seu papel de "coach", auxilie os discentes a interpretarem diferentes situações, reconhecendo as imagens que o livro didático traz, interpretando detalhes que se apresentam em cada espécie estudada.

Já a Tabela 5 relaciona o conhecimento científico, através da indagação: "Você acredita que a trilha trouxe conhecimento científico?".

Tabela 5: Faz referência ao conhecimento científico e a prática.

\begin{tabular}{ccc}
\hline $\begin{array}{c}\text { Conhecimento } \\
\text { científico e } \\
\text { prática }\end{array}$ & Quantidade & Percentual \\
\hline Sim & 35 & $100 \%$ \\
Em parte & 0 & $0 \%$ \\
Não & 0 & $0 \%$ \\
Total & 35 & $100 \%$ \\
\hline
\end{tabular}

Fonte: Elaborado pelos autores.

Em relação à tabela, nota-se que $100 \%$ dos discentes entenderam o intuito da atividade e atrelaram a mesma ao conhecimento científico, ou seja, consideraram positiva a relação entre a trilha e o conhecimento científico, principalmente no que se refere aos conceitos biológicos relacionados a Botânica e o arvorismo como atividade física. Compreendemos que o estudo da Botânica não é um dos mais apreciados pelos alunos, pois consiste em vocábulos estranhos. Dessa forma, tentamos utilizar uma nova forma de prática pedagógica para tornar esse conteúdo mais proveitoso e interessante. Nos deparamos com jovens que utilizaram seus celulares para manter outro tipo de contato, dessa vez com a natureza, por meio de fotos e vídeos durante o trajeto da trilha e arvorismo. Oportunizamos um estudo científico diferenciado, colaborativo, motivador onde ocorreu a construção e a reconstrução de significados. Assim, é fundamental a reorganização da prática docente, buscando alternativas para que suas disciplinas não se tornem maçantes. 
Segundo Demo (2009), a mudança é fundamental, é passar do livro texto, da apostila, do professor instrucionista, para um ambiente de produção própria colaborativa, sob orientação maiêutica. Não se prioriza transmissão de conteúdo; trata-se de os refazer, renovar, tornando-se o modo de aprender pelo menos tão importante quanto saber lidar com os conteúdos.

Por esses motivos, os sujeitos da educação precisam entender a escola como algo vivo, onde se vivenciam valores, onde se interage, se aprende, se constrói conhecimento de maneira dialógica, envolvente, onde se aprende fazendo, sentindo, interagindo (DALLA COSTA et al., 2017).

A pergunta 6 estava relacionada a trilha, arvorismo e interdisciplinaridade: "Você acredita que a trilha se tornou mais interessante com a atividade do arvorismo? A união das disciplinas foi importante para isso? Justifique:" (Tabela 6).

Tabela 6: Trilha e arvorismo

\begin{tabular}{ccc}
\hline $\begin{array}{c}\text { Trilha, arvorismo e } \\
\text { interdisciplinaridade }\end{array}$ & Quantidade & Percentual \\
\hline Sim & 27 & $77,14 \%$ \\
Em parte & 8 & $22,85 \%$ \\
Não & 0 & $0 \%$ \\
Total & 35 & $100 \%$ \\
\hline
\end{tabular}

Fonte: Elaborado pelos autores.

Em relação ao exposto, nota-se que $77,14 \%$ dos discentes entendeu que o arvorismo contribuiu para tornar a atividade mais interessante. Sabemos que os adolescentes apreciam desafios: realizar a trilha, fotografar espécies, caminhar sob as cordas tornou a atividade desafiadora, apontando novas possibilidades para sair da rotina em sala de aula.

Salientamos a importância entre a união das disciplinas, pois não conseguiríamos realizar a técnica de entrelaçamento de cordas entre árvores e a definição do trajeto da trilha sem o apoio do profissional de Educação Física. Da mesma forma, as espécies vegetais e suas relações ecológicas poderiam não ser observadas sem a participação de um biólogo. Conforme questionários, enfatizamos os seguintes comentários "Poderia ser só uma trilha", "no início, não compreendi a relação com a educação física"; "achei um pouco besta, mas confesso: amei passar entre as cordas e registrar o momento"; "momento único"; "jamais pensei em passar um dia assim", "amei tudo professores, parabéns"; "pena que estamos no terceirão e não teremos nova atividade assim"; "é preciso uma atividade dessas por mês".

Através desses relatos, compreende-se a importância dos profissionais das respectivas disciplinas e o olhar científico que determinou o sucesso da atividade. Faro (2017) contribui salientando que, no atual momento que a humanidade atravessa, não há outra atitude a tomar senão trabalharmos por 
uma sociedade informada, sustentável e consciente de seu pertencimento à escola da vida e de sua relação com o meio ambiente.

Nessa perspectiva, verificamos a importância de abordar a questão do meio ambiente e seus impactos, vivenciados na atualidade, buscando conscientização crítica dentro da sala de aula (SILVA, 2015).

O interesse pelas questões ambientais só ocorrerá a partir do momento em que se possa partilhar de momentos que favoreçam essa cognição. Desse modo, a interdisciplinaridade, o auxílio entre professores de diferentes áreas, a troca de experiências poderá favorecer a mudança de hábitos, além de proporcionar conhecimento.

Nogaro (2015) declara que o trabalho do professor não se resume à sala de aula ou ao seu discurso (ensinar), mas possui uma dimensão simultânea e complementar que é o seu "ser", como age, como transita e influencia por meio do exemplo, seja pessoal ou organizacional.

Nesse contexto, entendemos a relevância da docência, capaz de envolver os valores que emergem da sociedade, situando educador e educando com os problemas relacionados à cultura de cada sociedade, exigindo revisão das práticas adotadas costumeiramente, proporcionando aos discentes um agir consciente e responsável, convivência sadia, gestando as condições para um pensar crítico e reflexivo.

\section{Conclusão}

A atividade interdisciplinar "trilha interpretativa" proporcionou aos discentes, atividade física, ressignificação de conceitos biológicos relacionados ao ensino de Botânica, auxílio mútuo, aprendizagem, integração com a natureza.

Oportunizamos a Educação Ambiental em um espaço não formal, a vivência das relações que ocorrem no meio, a percepção da riqueza dos detalhes nas características de cada espécie, o entretenimento. Reafirmamos a importância do uso de diferentes ferramentas didáticas pelo docente, das práticas interdisciplinares para dar suporte e significação a cada disciplina.

Enfim, evidenciamos o prazer dos discentes em realizar a atividade, constatando que trilhas não servem apenas para entretenimento e sim como ferramenta para aprendizado e conhecimento. 


\section{Referências}

AGUIAR, P. C. B.; COSTA NETO, R. F.; BRUNO, N. L.; PROFICE, C. C. Da Teoria à Prática em Educação Ambiental. Rev. Gestão e Sustentabilidade Ambiental. Florianópolis, v.6, n.2, p.111 - 132, 2017.

BACICH, L.; MORAN, J. Metodologias ativas para uma educação inovadora: uma abordagem teórico-prática. Porto Alegre: Penso, 2018, p.29.

BOHRER, P. V.; KROB, A. J. D. Instrumentos de avaliação de resultados: conhecendo e aperfeiçoando a atuação do educador ambiental e do Instituto Curicaca. In: Cassiano Pamplona Lisboa; Eunice Aita Isaia Kindel (Org.). Educação Ambiental: da teoria à prática. 1 ed. Porto Alegre: Mediação, p. 8397. 2012.

BRANCALIONE, L. Educação Ambiental: refletindo sobre aspectos históricos, legais e sua importância no contexto social. Rev. Educação do IDEAU. Uruguai. v.11, n.23, p.1-13, 2016.

BRASIL. Parâmetros Curriculares Nacionais: apresentação dos temas transversais. Parâmetros curriculares nacionais: meio ambiente, saúde. Secretaria de Educação Fundamental. Brasília: MEC/SEF, 1997.

CAMPOS, R. F.; FILLETO, F. Análise do perfil, da percepção ambiental e da qualidade da experiência dos visitantes da Serra do Cipó (MG). Revista Brasileira de Ecoturismo. v.4, n.1, p.69-94, 2011.

CORTI, A. P.O.; SOUZA, R. Diálogos com o mundo juvenil: subsídios para educadores. 2 ed. São Paulo: Ação Educativa, 2012, p.33.

COSTA, E. S. A.; COSTA, I. A. S.; OLIVEIRA, K. S.; MELO, A. V.Trilhas interpretativas na área verde da escola como estratégia de ensino para aprendizagem de conceitos ecológicos. Revista da SBEnBIO. n.7, v.1. Enebio e II Enebio Regional 1. Universidade do Rio Grande do Norte - UFRN, 2014, p.110.

DALLA COSTA, A. A.; SILVA, J. C..; MIOLA, A.; KUHNEN, R.; HAUSCHILDT, G. Z. T. Educação Humanizadora: valorizando a vida na sociedade contemporânea. In: VII CONGRESSO INTERNACIONAL DE EDUCAÇÃO, Santa Maria, 2017. Anais ... Santa Maria: Biblos, 2017, p.68.

DEMO, P. Educação Hoje: novas tecnologias, pressões e oportunidades. São Paulo: Atlas, 2009, p.31.

EISENLOHR, P.V.; MEYER, L.; MIRANDA, P.L.S.; REZENDE, V.L. et al. Trilhas e seu papel ecológico: o que temos aprendido e quais as perspectivas para a restauração dos ecossistemas? Rev. Hoehnea. v.40, n.3, p.407-418, 2013.

FARO, I.F. Educação para o Meio Ambiente. Campinas, SP: Pontes Editores, 2017. 
FAZENDA, I.; CASADEI, S. R. Natureza e Interdisciplinaridade: reflexões para a Educação Básica. Rev. Interdisciplinaridade. São Paulo, v.1, n. 2, 2012, p.46.

FORTUNATO, R.; CONFORTIN, R.; SILVA, R. T. Interdisciplinaridade nas escolas de educação básica: da retórica à efetivação pedagógica. REI (Revista de Educação do Ideau). v.8, n.17, p.2-15, 2013.

HARARI, Y. N. Sapiens: Uma breve história da Humanidade.. Porto Alegre: L\&M, 2018, p. 469.

LAZZARI, G.; GONZATTI, F.; SCOPEL, J. M.; SCUR, L. Trilha ecológica: um recurso pedagógico no ensino de Botânica. Scientia Cum Industria. v.5, n.3, p. 161-167, 2017.

LEFF, E. Aventuras da epistemologia ambiental: da articulação das ciências ao diálogo dos saberes / Tradução de Silvana Cobucci Leite. São Paulo: Cortez, 2012, p.90.

LIEFLÄNDER, A. K.; BOGNER, F. X. The effects of children's age and sex on acquiring pro-environmental attitudes through environmental education. The Journal of Environmental Education. 2014, v.45, n.2, p. 105-117.

LIEFLÄNDER, A. K.; FRÖHLICH, G.; BOGNER, F. X.; SCHULTZ, P. W. Promoting connectedness with nature through environmental education. Environmental Education Research. 2013, v.19, n.3, p. 370-384.

LISBOA, C. P.; KINDEL, E. A. I. (org.). Educação Ambiental: da teoria à prática. Porto Alegre: Mediação, 2012, p.25.

MARTINS, E. C.; TAVARES, D. E. A escuta sensível - prática do docente interdisciplinar no ensino médio. Rev. Interdisciplinar. São Paulo, v.1, n.6, abril, 2015.

NOGARO, A. O compromisso ético do educador na e para com a educação na sociedade líquida. In: Antônio Amélio Dalla Costa, Jadir Zaro e Jolair da Costa Silva (org.) Educação Humanizadora e os desafios da sociedade pósmoderna. Santa Maria: Biblos, p. 56-71, 2015.

OLSSON, D.; GERICKE, N. The adolescent dip in students' sustainability consciousness-Implications for education for sustainable development. The Journal of Environmental Education. 2016, v.1, n.47, p.35-51.

ROCHA, M. B.; ROBERTO, L. H.; QUITÁ, C.; SILVEIRA, L. F., VASCONCELLOS, V. Estudos sobre trilhas: uma análise de tendências em eventos de Ensino de Ciências e Educação Ambiental. Acta Scientia. Canoas v.18 n.2 p.517-530, maio/ago. 2016.

SANTOS, M. C.; FLORES, M. D.; ZANIN, E. M. Trilhas Interpretativas como instrumento de interpretação, sensibilização e Educação Ambiental na APAE de Erechim/RS. Vivências. v.7, n.13: p.189-197, Outubro/2011. 
SANTOS, R. L. F.; ALMEIDA, R. C. Educação Ambiental e Trilhas Ecológicas: o caminhar para um futuro consciente e sustentável. Revista Científica do Unisalesiano. Lins - SP, ano 2, n.4, p.265-276, jul/dez, 2011.

SILVA, F. W. Corpo e Natureza: perspectiva para uma educação do Corpo Mundo. 2007. Florianópolis, 2007. 155f. Dissertação (Mestrado em Educação Física)- Universidade Federal de Santa Catarina, p.139.

SILVA, F. W.; SAMMARCO, Y. M.; TEIXEIRA, A. F. Educação Ambiental lúdica: diálogos do corpo, lazer e arte. In: Cassiano Pamplona Lisboa; Eunice Aita Isaia Kindel (Org.). Educação Ambiental: da teoria à prática. 1 ed. Porto Alegre: Mediação, p. 49-69. 2012.

SILVA, N.C. O despertar da conscientização ambiental no ensino de Geografia. Revbea. São Paulo: v.10, n.1, 2015, p.76.

SOUZA, M. C. C. Educação Ambiental e as trilhas: contexto para a sensibilização ambiental. Revbea. São Paulo, v.9, n.2, p.239-253, 2014.

UITTO, A.; SALORANTA, S. The relationship between secondary school students' environmental and human values, attitudes, interests and motivations. Procedia-Social and Behavioral Sciences. v.9, n.0, p. 1866-1872, 2010. 